\title{
Statistical downscaling of probability density function of daily precipitation on the Polish coast
}

\author{
Wójcik Robert \\ Institute of Meteorology and Water Management, National Research Institute, Maritime Branch in Gdynia, Waszyn- \\ gtona Street 42,81-342 Gdynia, Poland, e-mail: robert.wojcik@imgw.pl
}

Pilarski Michał

Institute of Meteorology and Water Management, National Research Institute, Podleśna Street 61, 01-673 Warszawa, Poland

Miętus Mirosław

University of Gdańsk, Institute of Geography, Department of Meterology and Climatology, Bażyńskiego Street 4, 80-309 Gdańsk, Poland

\begin{abstract}
The aim of this study was to recognize the possibility of downscaling probability density function (PDF) of daily precipitation by means of canonical correlation analysis (CCA). Sea level pressure (SLP) over Europe and the North Atlantic was used as a predictor. A skilful statistical model could be used to generate projections of future changes of precipitation PDF driven by GCM (General Circulation Model) simulations.

Daily precipitation totals from 8 stations located on the Polish coast of the Baltic Sea covering the period 1961-2010 were used to estimate the gamma distribution parameters, and only wet days (i.e. $\geq 0.1 \mathrm{~mm}$ ) were taken in the analysis. The results of the Kolmogorov-Smirnov test and comparison of empirical and theoretical (gamma-distributed) quantiles proved that gamma distribution gives a reliable description of daily precipitation totals.

The validation of CCA models applied to gamma parameters revealed that the reliable reconstruction of precipitation PDF is possible only for average long-term conditions. In the case of individual months/seasons the agreement between empirical and reconstructed quantiles is poor. This study shows the potential of modelling of precipitation PDF, however efforts should be made to improve model performance by establishing more reliable links between regional forcing and the variability of the gamma parameters.
\end{abstract}

Key words: statistical downscaling, canonical correlation, precipitation totals, probability density function, gamma distribution

Submitted 16 October 2013, revised 20 May 2014, accepted 29 May 2014

\section{Introduction}

The considerable variability of precipitation is of great interest as it has strong and direct economic, social and environmental impacts. Great importance is especially attached to the occurrence of extreme precipitation events and droughts. The former may trigger floods of various spatial scales with considerable infrastructure losses and possible human fatalities. Significant increase in flood damage has been observed worldwide in recent decades, however only part of this trend is associated with an increase in intense precipitation events (Kundzewicz et al. 2006). Droughts may lead to water stress as a consequence of the reduction of freshwater resources available to a population, agriculture and industry. It is expected that precipitation extremes will intensify in a warming climate, as higher temperatures will lead to a significant increase in atmospheric water vapour content. This thesis is supported by some evidence, mainly model simulations (e.g. Fowler et al. 2007; Pall et al. 2007; O`Gorman, Schneider 2009). However on the basis of instrumental data from Poland it is evident that precipitation patterns are far less sensitive to greenhouse forcing than air temperature. While air tem- perature in Poland has exhibited a pronounced upward trend since the mid-20th century, changes of precipitation totals and the number of days with extreme precipitation are insignificant and spatially incoherent (Marosz et al. 2011). The dominance of long-term (1951-2006) decreasing tendencies of various indices of extreme precipitation in Poland was shown by Łupikasza (2010).

The main idea behind modelling precipitation totals, as well as the occurrence of extreme events, is to create the basis for the development of projections of future changes. Global climate models (GCMs), despite some uncertainties about their reliability (e.g. Räisänen 2007), are practically the only source of information about a possible future climate that has undergone the changes of natural and greenhouse forcing. However, due to the still relatively low horizontal resolution, the spatial distribution of climatic elements in GCMs simulations is generalised and thus insufficient for impact applications. Especially large uncertainties may occur in a heterogeneous environment with complex physiography or steep environmental gradients (like mountainous regions, sea coasts). Application of downscaling procedures is thus needed to provide spatially accurate information about simulations of the 
variable under consideration. Statistical downscaling is one of the possibilities, with relative ease of use, low costs and low computation demands among its main advantages - they make it a suitable tool for generating multiyear series and for exploring a wide range of different GCM simulations (e.g. Benestad 2004). It is however acknowledged that the general performance of statistical downscaling models of indices of precipitation extremes is poor (STARDEX 2005), with better results for indices indicative of rainfall occurrence than those of intensity (Haylock et al. 2006). The alternative approach is the modelling of probability density functions (PDF) of selected elements, allowing the estimation of future changes of selected distribution measures (including median, quantiles and extremes) or even mean and variance. Maraun et al. (2010) concludes that statistical techniques that provide the ability to generate complete distributions should be used as a default, especially when information on extremes is required. In the case of daily precipitation several theoretical distributions have been previously used, but probably the most popular one is the gamma distribution (e.g. Mooley 1973; Groisman et al. 1999; Katz 1999; Semenov, Bengtsson 2002; Zolina et al. 2004; Benestad et al. 2005; Husak et al. 2007). The advantages of this distribution are that, like daily precipitation totals, it is bounded on the left at zero, is positively skewed and, most importantly, offers the possibility of describing a wide range of distribution shapes (Husak et al. 2007). Thus, it is commonly thought that daily precipitation totals follow the gamma distribution - however, a recent study by Vlček and Huth (2009) proved that the validity of the gamma distribution is questionable, as, for example, winter daily precipitation does not have the gamma distribution at more than $40 \%$ of examined stations across Europe.

The goal of this paper is the recognition of the possibility of applying canonical correlation analysis (CCA) to downscale probability density function of daily precipitation. Relying upon available literature, the gamma distribution was chosen to fit the distribution of daily precipitation totals. The analysis was carried out for stations located along the Polish coast of the Baltic Sea and was mainly focused on the upper tail of the distribution i.e. 90th percentile, which can be regarded as an indicator of moderate climate extremes (Haylock, Goodess 2004), whereas investigating more extreme events and their relation to climate variability could give erratic results. The development of a skilful statistical model would be of appreciable value, as it could be used to generate projections of future changes of precipitation PDF, giving the opportunity to quantify precipitation extremes in the future. A similar study for air temperature and normal distribution was recently carried out by Marosz et al. (2012) and Marosz and Jakusik (2014). An attempt to directly downscale (reconstruct) the occurrence of extreme daily precipitation in Poland has provided rather unsatisfactory results (Marosz et al. 2013), so alternative approaches (as in this paper) should be tested.

\section{Data and methods}

The Daily precipitation totals from 8 stations located on the Polish coast of the Baltic Sea (Fig. 1) covering the period 1961-2010 were used to estimate the gamma distribution parameters for each month. Single missing data were recorded only in Świnoujście (VII.1994), Kołobrzeg (XII.1994) and Darłowo (VI.1992). The parameters of the gamma distribution, estimated separately for each month, were merged into three-month seasons: winter (DecemberFebruary, further referred as $D J F$ ), spring (March-May, $M A M$ ), summer (June-August, $J J A$ ) and autumn (September-November, $S O N)$.

The two-parameter gamma distribution is characterized by the shape parameter $\alpha$ and scale parameter $\beta$. The probability density function for the distribution is:

$$
f(x)=\frac{\left(\frac{x}{\beta}\right)^{\alpha-1} \exp \left(\frac{-x}{\beta}\right)}{\beta \Gamma(\alpha)}
$$

where $\mathrm{x}>0$ is precipitation total, $\alpha$ is the shape parameter, $\beta$ is the scale parameter and $\Gamma(\alpha)$ is the gamma function. Depending on the value of the dimensionless shape parameter $\alpha$, the PDF of the gamma distribution takes on a variety of shapes - ranging from hyperbolically increasing (when $\alpha<1$ ) and exponential distribution (when $\alpha=1$ ) to near normal distribution (for very high values of $\alpha$ ) (Semenov, Bengtsson 2002). The scale parameter $\beta$ depends on the magnitude of data values and it stretches or squeezes the distribution. It has the same physical dimension as $x$ (Wilks 2006). Generally the growing $\alpha$ results in higher probability of extreme values, while the increase of $\beta$ implies higher occurrence of extremes. Nevertheless the combined effect of the parameters on the occurrence of extremes remains complicated (Zolina et al. 2004). The R Project for Statistical Computing software package "fitdistrplus" was used to estimate $\alpha$ and $\beta$ with the maximum likelihood method, which is considered the most efficient.

The limitation of the gamma distribution is that it is applicable only to non-zero precipitation totals, so a sample size for the estimation of parameters varies accordingly to the number of wet days (i.e. $\geq 0.1 \mathrm{~mm}$ ). Unfavourably the number of wet days is characterized by a pronounced variability on the monthly scale. The average (1961-2010) monthly number of wet days (and sample size at the same time) on the Polish coast varies from about 13 in spring and summer to about 17 in winter. However in individual months it may range from only 1 up to 29 wet days, thus in many cases the low number of wet days may lead to a highly unrealistic estimation. Vlček and Huth (2009) suggest rejection of samples of less than 10 values, however in this study, in order to retain the data series continuity, the recommendation of Essenwanger (1986) of a minimum of 5 values was followed.

The reliability of parameter's estimation was tested with the use of the Kolmogorov-Smirnov goodness-of-fit 


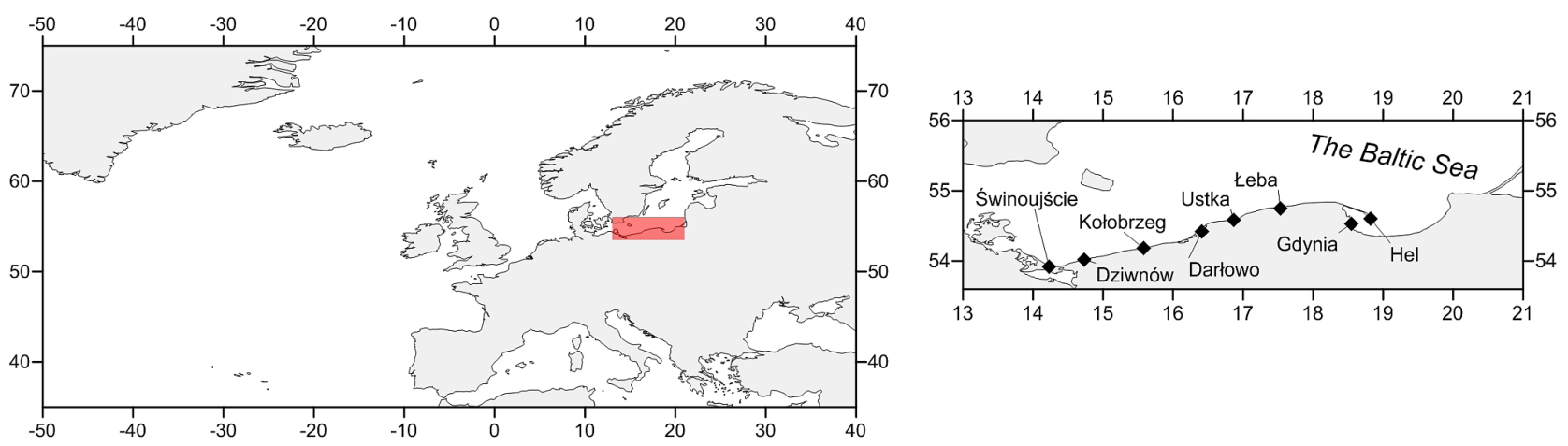

Fig. 1. Spatial domain of predictor (left map) and localization of predictand stations (right map)

test, in order to verify whether the estimated theoretical function (gamma distribution) is consistent with the distribution of empirical data (precipitation totals in a given month). In the K-S test, the testing statistic is the maximum difference between the empirical and theoretical distribution functions. In this paper, the validity of the gamma distribution was tested at significance level $\alpha=0,05$. Critical values of the K-S test, due to limitations of the use of the K-S test when the parameters of the distribution functions are estimated from the same dataset on which they are tested (leading to type II error), were adjusted in accordance with the Lilliefors test and taken after Crutcher (1975). They are, however, given only for sample size of 25 and 30, so for different (smaller) samples critical values were determined, similarly to Vlček and Huth (2009), by multiplying asymptotic values (given by Crutcher 1975) by $(1 / N)^{1 / 2}$, where $\mathrm{N}$ is a sample size. The results of the $\mathrm{K}-\mathrm{S}$ test indicate that precipitation distribution in $>95 \%$ of months follow the gamma distribution (i.e. there is no reason to reject the null hypothesis that empirical and theoretical distributions are similar), with the only exception found in case of Gdynia in DJF (87\%). The rejected cases (months) were removed from data series and were not taken into consideration in the subsequent analyses.

The relationship between gamma distribution parameters and regional climatic conditions was examined by means of canonical correlation analysis (CCA). The CCA is a multivariate linear regression method used to investigate the relationship between a large-scale climate variable and regional/local climate conditions. It is based on selection of pairs of optimally correlated spatial patterns, including regional forcing and local variable. Detailed mathematical insight into CCA was provided by e.g. von Storch (1995) or Wilks (2006). The CCA, due to the ease of physical interpretation of identified relations, is one of the most frequently used methods of statistical-empirical downscaling. Sea level pressure (SLP) over Europe and the northern Atlantic was chosen as a regional forcing (Fig. 1), as changes of atmospheric circulation are the main factor determining short-term climate variability in Poland. The applicability of CCA to investigate links between the regional SLP field and climate elements in Poland was confirmed by e.g. Filipiak (2004), Miętus et al. (2008, 2010), Biernacik et al. (2010). Monthly SLP data covering the 1961-2010 period was acquired from NCEP reanalysis with grid resolution $2.5^{\circ} \times 2.5^{\circ}$ (Kalnay et al. 1996). Prior to the CCA, data series of predictor and predictand were converted into monthly anomalies (to remove annual cycle), detrended and filtered by means of Empirical Orthogonal Functions (EOF). As a result. the data dimension was reduced to a few main and mutually independent patterns of spatial and temporal variability (e.g. Werner, von Storch 1993; Busuioc et al. 1999). Separate CCA models were developed for $\alpha$ and $\beta$ as well as for different seasons. The cross-validation technique was used to optimise the models in terms of the number of EOFs entering CCA and retained CCA pairs. The models were calibrated on data from the period 1971-2000.

\section{Results}

a. Selected features of pluvial conditions on the Polish coast Despite relatively small scale and considerable environmental homogeneity of the Polish coast, the pluvial conditions in this area are substantially diversified. This can be clearly seen even when mean (1961-2010) annual precipitation totals are considered, as they reach 560-580 $\mathrm{mm}$ in the western part (Świnoujście and Dziwnów), abruptly rise to over $650 \mathrm{~mm}$ in the central part, with the maximum of $700 \mathrm{~mm}$ in Ustka, and fall below $600 \mathrm{~mm}$ in the vicinity of the Bay of Gdańsk (Hel - $587 \mathrm{~mm}$, Gdynia - $538 \mathrm{~mm}$ ). In the annual course (Fig. 2), the lowest average monthly precipitation totals are recorded in February, ranging from $22.6 \mathrm{~mm}$ in Gdynia to $35.7 \mathrm{~mm}$ in Kołobrzeg, and it is only in Darłowo and Ustka that the minimum occurs in April (33.8 $\mathrm{mm}$ and $35.3 \mathrm{~mm}$ respectively). There is a much more pronounced spatial variability in terms of the wettest month, as maximum mean precipitation occurs in July (Dziwnów, Kołobrzeg, Darłowo, Gdynia), August (Świnoujście, Hel) or even in September (Ustka, Łeba) with values ranging from $58.4 \mathrm{~mm}$ (Świnoujście) to $82.5 \mathrm{~mm}$ (Kołobrzeg). With respect to the annual course of mean monthly precipitation totals, stations used in the present study can be categorized into three fairly different rainfall regimes:

1. with the highest $(55-65 \mathrm{~mm} / \mathrm{month})$ precipitation totals in summer and relative small annual amplitude (Świnoujście, Dziwnów; Fig. 2a), 


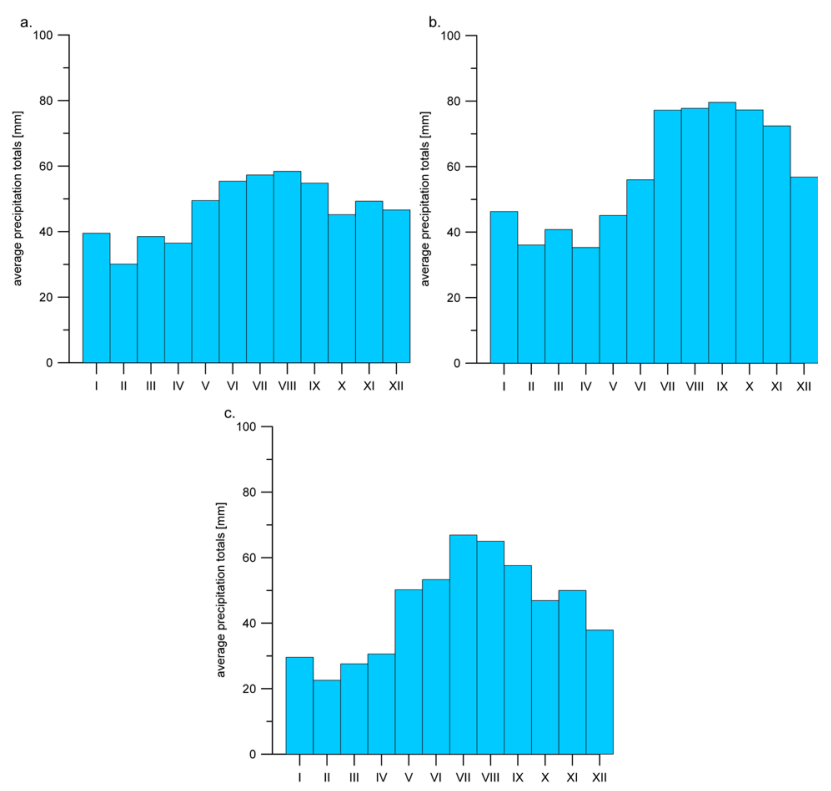

Fig. 2. Average monthly precipitation totals in Świnoujście (a), Ustka (b) and Gdynia (c) (1961-2010)

2. with high precipitation totals from July to November (65-80 mm/month) and high annual amplitude (Darłowo, Ustka, Łeba and, to lesser extent, Kołobrzeg; Fig. 2b),

3. characterized by clear peak of precipitation totals in July and August and relatively large annual amplitude (Hel, Gdynia; Fig. 2c).

The differentiation of pluvial conditions along the Polish coast was previously noticed by Miętus et al. (2005) in terms of temporal evolution, and by Pilarski et al. (2011) in terms of spatial distribution precipitation totals.

The absolute maximum daily precipitation totals (1961-2010) on the Polish coast are clearly seasondependent (Tab. 1). In winter the highest daily precipitation exceeded $20 \mathrm{~mm}$ on all stations under consideration, with the highest values in Dziwnów and Leba $(31.6 \mathrm{~mm}$ and $32.2 \mathrm{~mm}$ respectively). In spring, except for in Kołobrzeg, absolute maximums reached about 40-50 mm (in April or May). The highest precipitation totals with the greatest spatial diversity at the same time were recorded during summer. The highest absolute daily values ranged from about $60 \mathrm{~mm}$ in Świnoujście and Dziwnów, to around $76 \mathrm{~mm}$ in Hel and Gdynia to $105 \mathrm{~mm}$ in Darłowo and up to as much as $141 \mathrm{~mm}$ in Łeba. In autumn the highest precipitation totals varied from below $50 \mathrm{~mm}$ (Świnoujście,
Ustka, Łeba), to about $80 \mathrm{~mm}$ in Hel and Gdynia. With the exception of Łeba, absolute maximum precipitation in autumn was recorded in September. It is worth noting that in Hel and Gdynia values for autumn slightly exceeded the summer maximum. The varied dates of those events indicate that maximum daily precipitation totals did not occur simultaneously on the Polish coast - and this is evidence of the local-scale nature of extreme precipitation events. A pronounced example of spatial variability of precipitation is the urban flash flood in Gdańsk on $9^{\text {th }}$ July 2001, when daily precipitation total in Gdańsk-Rębiechowo reached $127.7 \mathrm{~mm}$, while being substantially lower in Gdynia (37.7 mm, approximately $20 \mathrm{~km}$ away in a straight line) and in Hel (24.3 mm, approx. $30 \mathrm{~km}$ away) (Ziemiański, Wójcik 2003), while in Łeba (approx. $85 \mathrm{~km}$ away) no rainfall was recorded at all. The majority of events listed in Tab. 1 were recorded in the last two decades of the period 1961-2010, particularly in the 1990s.

\section{b. Empirical vs. theoretical values}

A brief comparison of empirical and theoretical percentiles of precipitation totals was undertaken to additionally assess the accuracy of gamma distribution estimation. The gamma-modelled values fit the empirical data really well as only insignificant deviations from the perfect match line appear (Fig. 3). Theoretical values tend to slightly overestimate real precipitation totals, especially lower and middle percentiles. Underestimation takes place only in the upper tail of distribution (i.e. the $95 \%$ percentile). Overall, the best agreement between theoretical and empirical values occur in the case of the $90 \%$ percentile, thus it can be stated that the gamma distribution is suitable for approximating precipitation extremes on the Polish coast.

More detailed insight into the quality of the estimation of the $90 \%$ quantile shows that in cases of individual months the differences between empirical and theoretical values may become significant, especially in summer (Fig. 4). However a coefficient of determination $\left(R^{2}\right)$ values exceeding 0.80 or even reaching 0.90 prove that evident linear dependency exists. In summer $R^{2}$ value drops to 0.74 , but gamma-distributed values can still be regarded as a good approximation of extreme precipitation events. The common feature for all seasons is a weak tendency to overestimate small values of the $90 \%$ quantile and underestimate extremes (as indicated by a fit line).

Tab. 1. Absolute extreme daily precipitation totals $[\mathrm{mm}]$ in the 1961-2010 period and the date of occurrence (in brackets)

\begin{tabular}{|l|c|c|c|c|}
\hline & DJF & MAM & JJA & SON \\
\hline Świnoujście & $20.9(18 . I .2007)$ & $37.7(7 . I V .2008)$ & 58.7 (29.VIII.1969) & $44.7(3 . I X .1995)$ \\
\hline Dziwnów & $31.6(29 . X I I .2001)$ & $45.5(7 . I V .2008)$ & $66.4(16$. VII.1995) & $60.0(6 . I X .1996)$ \\
\hline Kołobrzeg & $25.5(4 . X I I .1980)$ & $31.8(10 . I V .1970)$ & $85.2(9$. VII.1996) & $67.6(1 . I X .1992)$ \\
\hline Darłowo & $24.0(18 . I .2007)$ & $37.2(17 . V .1967)$ & $105.0(28 . V I .1991)$ & $52.5(3 . I X .1995)$ \\
\hline Ustka & $28.0(20 . I I .1996)$ & $46.9(13 . V .1995)$ & $94.2(24 . V I I .1988)$ & $48.1(1 . I X .1992)$ \\
\hline Łeba & $32.2(4 . X I I .1999)$ & $51.8(28 . V .2002)$ & $141.0(24 . V I I .1988)$ & $44.6(4 . X .1975)$ \\
\hline Hel & $20.9(4 . X I I .1999)$ & $39.0(15 . V .1999)$ & $76.4(10$. VII.1980) & $77.1(27 . I X .2010)$ \\
\hline Gdynia & $29.9(18 . X I I .1962)$ & $42.4(13 . V .1995)$ & $76.3(10 . V I I .1980)$ & $82.1(27 . I X .2010)$ \\
\hline
\end{tabular}


Świnoujście

(a)

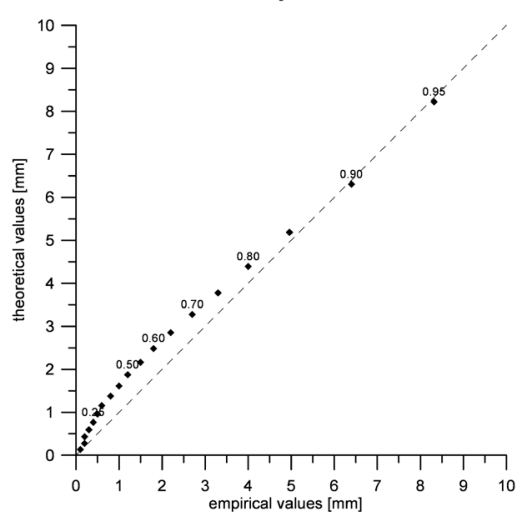

(b)

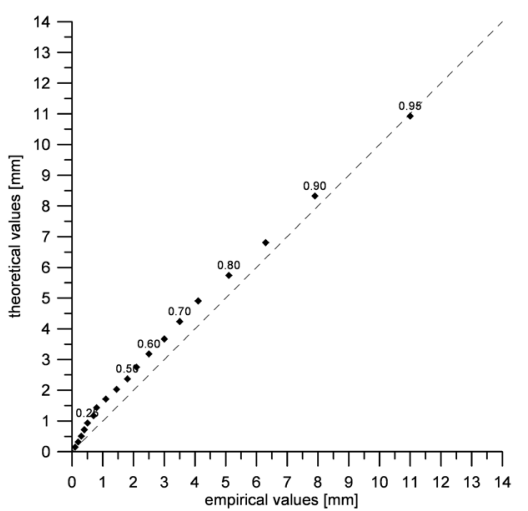

(c)

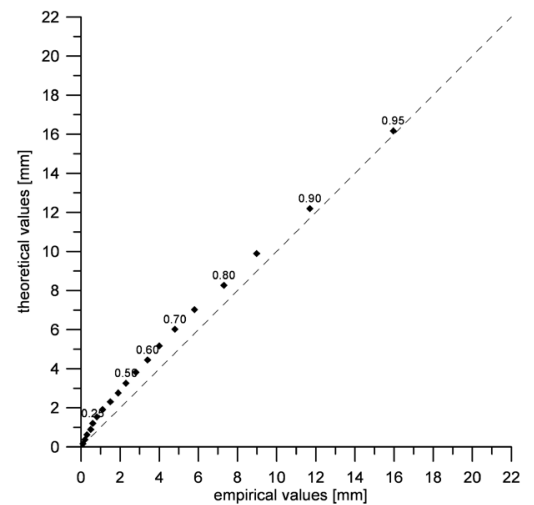

(d)

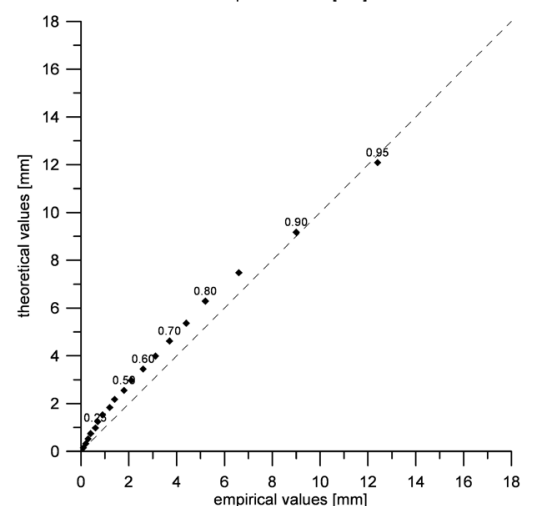

Ustka
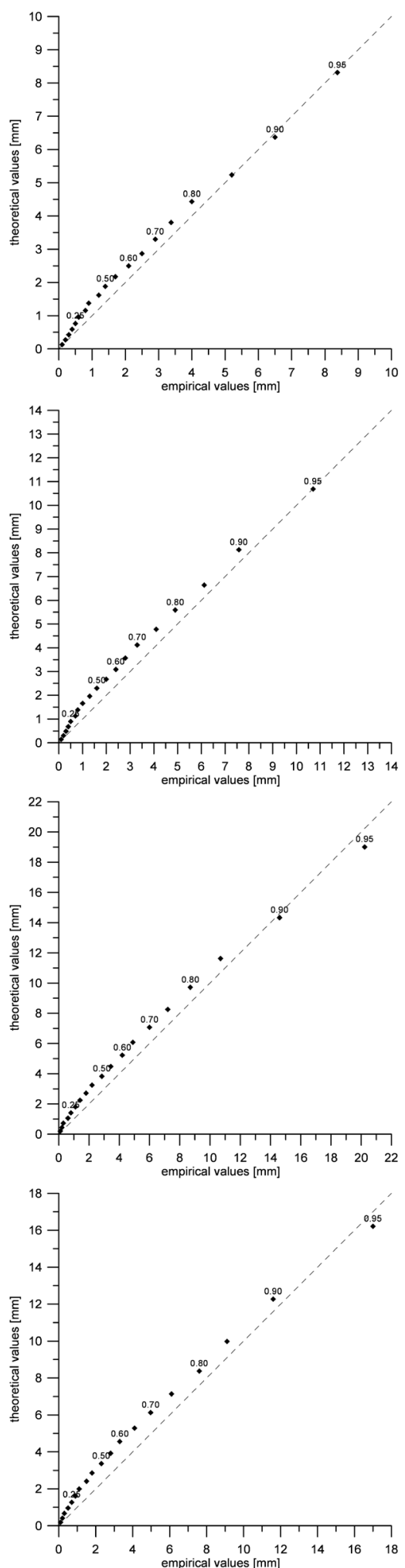

Gdynia
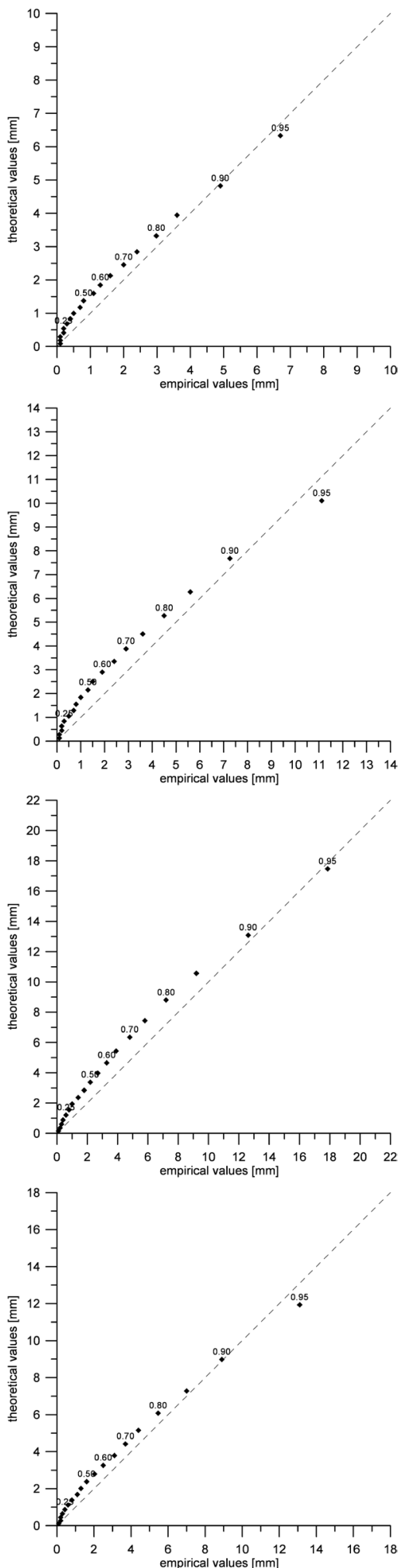

Fig. 3. Q-Q plot of empirical and theoretical (estimated from gamma parameters) values in Świnoujście, Ustka and Gdynia (19612010). The values are given every $5 \%$ ranging from $5 \%$ to $95 \%$. The perfect match line (dashed) is marked. (a) DJF, (b) MAM, (c) JJA, (d) SON 

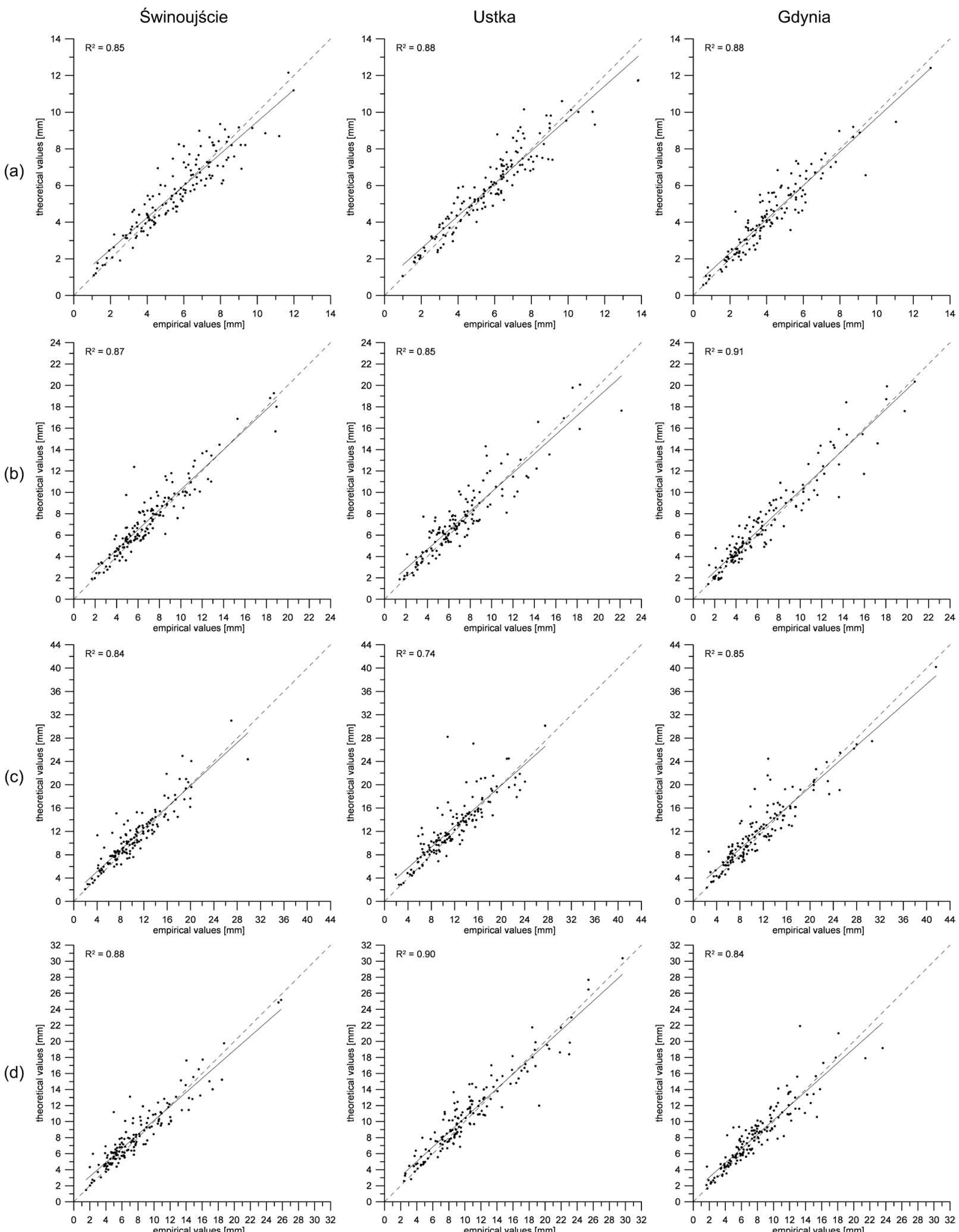

Fig. 4. Empirical and theoretical (estimated from gamma parameters) monthly values of $90 \%$ quantile of daily precipitation totals in Świnoujście, Ustka and Gdynia (1961-2010). Fitted line (solid) and perfect match line (dashed) are given. (a) DJF, (b) MAM, (c) JJA, (d) SON 
(a)

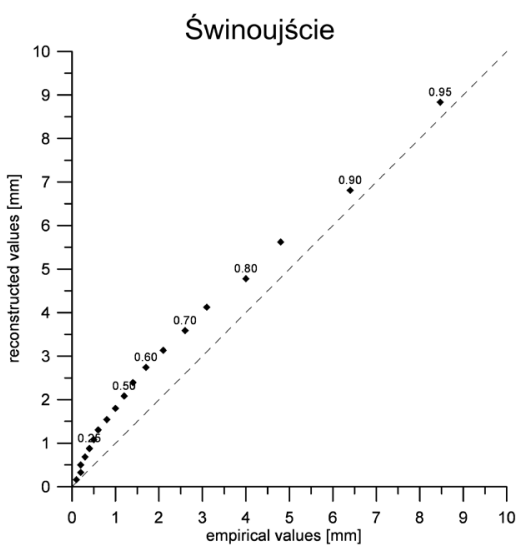

(b)

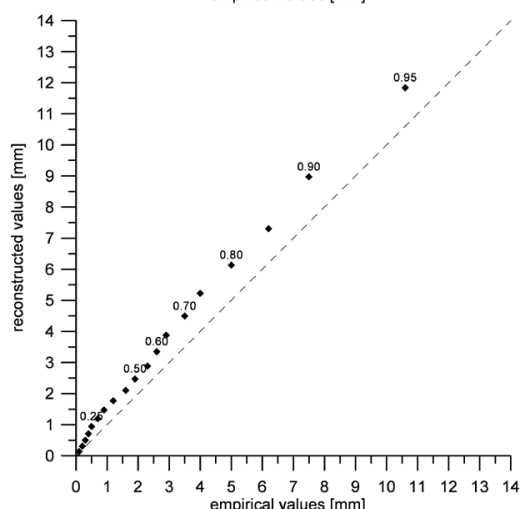

(c)
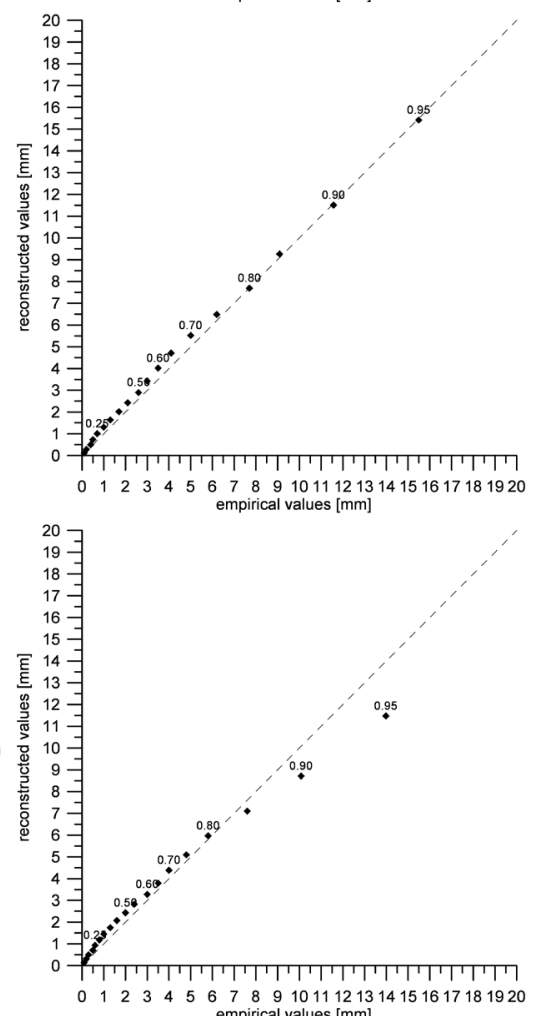
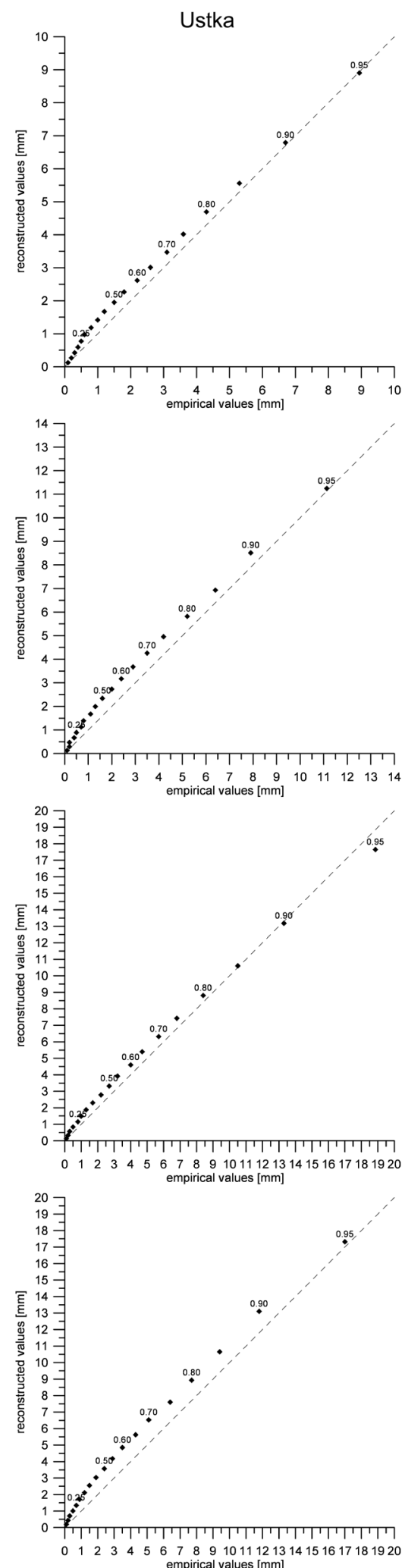

Gdynia
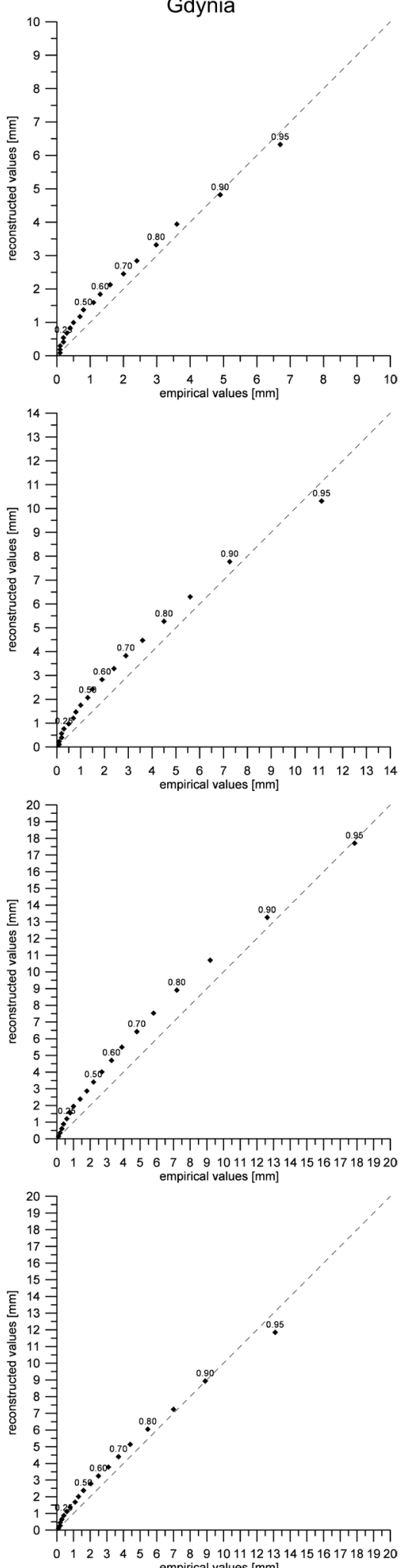

Fig. 5. Q-Q plot of empirical and reconstructed (estimated from reconstructed gamma parameters) values in Świnoujście, Ustka and Gdynia, independent data (1961-1970 and 2001-2010). The values are given every 5\% ranging from 5\% to $95 \%$. The perfect match line (dashed) is marked. (a) DJF, (b) MAM, (c) JJA, (d) SON 
c. CCA model

Prior to the CCA, EOFs were calculated for gamma distribution parameters in order to investigate whether $\alpha$ and $\beta$ series on the Polish coast represent spatial patterns of joint variance. Clear domination of one or a few EOFs would indicate strong common features of spatial-temporal variability among analyzed stations, giving evidence of the significant role of regional forcing in shaping $\alpha$ and $\beta$ values.

The maximum possible number of 8 EOFs describe the variability of $\alpha$ and $\beta$, indicating that precipitation PDF on a given station exhibits noticeable individual features. The leading EOF, showing a uniform sign of anomalies (except for $\alpha$ in DJF and MAM), explains about 30\% (SON) to nearly $60 \%$ (MAM) variance of $\alpha$ and about $50 \%$ variance of $\beta$ regardless of the season. Thus, no more than $50 \%$ of joint variation can be associated with regional scale forcing i.e. on a spatial scale greater than the Polish coast. Furthermore it is evident that JJA and SON precipitation, characterized by the highest extreme values, exhibits pronounced local features as the leading EOF is not clearly distinguished (especially in the case of $\alpha$ ) and a considerable share of variance is explained by all subsequent modes.

CCA model based on 1971-2000 data was developed separately for $\alpha$ and $\beta$ in order to investigate relationships between the variability of gamma distribution parameters and regional atmospheric circulation, defined by sea level pressure (SLP) values. Since the performance of the downscaling model depends on the number of the regional and local field EOFs retained for the CCA (e.g. Busuioc et al. 1999; Huth 1999), a cross-validation procedure was employed to establish the strongest possible links between regional forcing and a local variable.

The best models differ significantly in terms of the number of EOFs used in the model and a number of retained CCA pairs, both seasonally and between $\alpha$ and $\beta$.

The best model skill in terms of reconstructing precipitation PDF was evaluated by comparing values of empirical quantiles and those estimated from reconstructed gamma parameters. The estimation was made by taking mean values of reconstructed $\alpha$ and $\beta$ from 20-year long independent data series (1961-1970 and 2001-2010). In the examples presented in Figure 5 it can be shown that empirical and modelled quantile spectrums, reflecting 20year precipitation PDF, stay in good agreement as differences are generally fairly small. Especially the upper tail of distribution exhibits good approximation. In some cases the reconstructed results tend to overestimate values in the whole quantile spectrum, and especially large differences occur when the lower and middle percentiles are considered (e.g. Świnoujście in DJF, Gdynia in MAM and JJA, Ustka in SON). Nevertheless, it can be concluded overall that the reconstructed gamma parameters give a reliable and seasonally persistent representation of long-term precipitation PDF. Insight into agreement between empirical and reconstructed values of quantiles for individual months, however, brings disappointing results. The empiri- cal and mo-delled values of $90 \%$ quantile are virtually independent as $R^{2}$ drops below 0.1 and the best fit line is parallel to the $\mathrm{X}$ axis (not shown), indicating that for a given month the reconstructed and the empirical value may differ significantly. It can be concluded that that CCA models are capable of reconstructing reliable multiyear precipitation PDF, but are unable to reproduce short-term variability of precipitation distribution.

\section{Discussion and conclusions}

It seems that precipitation on the Polish coast is gamma-distributed (as proven by the KolmogorovSmirnov test) and that quantiles of monthly precipitation can be reliably estimated from gamma parameters (Fig. 3, 4). An attempt to downscale precipitation PDF brings more ambiguous results. The validation of CCA models applied to gamma parameters revealed that the reliable reconstruction of precipitation PDF is possible only when average multiyear conditions are considered (fFg. 5), while in the case of individual months/seasons the agreement between empirical and reconstructed quantiles is poor, at least the in case of extreme precipitation events. Thus it can be stated that CCA models precisely reproduce the long-term average values of gamma parameters, but neglect the short-term variability of precipitation distribution. Reliable multiyear information may be sufficient in the context of developing climate change projections driven by GCM simulations, however the applicability of the developed CCA models to produce reliable projections of precipitation PDF changes is uncertain (even for multiyear periods). The key question is whether gamma parameters are determined by large scale conditions or whether individual, local features prevail. EOF analysis applied to series of gamma parameters indicates that a considerable share of variance may be associated with regional forcing. Benestad et al. (2005) found that shape parameter $(\alpha)$ exhibits a relationship with the circulation patterns while scale parameter $(\beta)$ is not sensitive to large-scale circulation.

In order to develop a more skilful statistical model it seems necessary to improve model performance in terms of reconstruction of short-term variability i.e. to establish reliable links between predictor and gamma parameters. Among possible solutions the selection of other predictors seems to be the most promising, as the choice of an informative predictor is crucial for the credibility of downscaled time series (e.g. Wilby, Wigley 2000; Hanssen-Bauer et al. 2003; Benestad 2007; Maraun et al. 2010). In the recent Sauter and Venema (2011) study vertical velocity at $500 \mathrm{hPa}$ level and geopotential heights $(300 \mathrm{hPa}$ and $500 \mathrm{~Pa})$ were found to be influential predictors in precipitation downscaling, while the importance of the inclusion of tropospheric humidity information was emphasized by e.g. Charles et al. (1999) and Hanssen-Bauer et al. (2005). An increase in the number of precipitation series, in order to provide a more comprehensive insight into spatial variability patterns, could also improve model performance. 
Another possible reason for the unsatisfactory reconstruction of short-term variability of gamma parameters is that the parameters were estimated for wet days only (dry days were ignored), while the predictor values (SLP) were averaged over the whole month. In this way, the impact of SLP changes on parameters of distribution may have been attenuated. To avert this problem, an attempt to estimate gamma parameters for both wet and dry (marked as $0.001 \mathrm{~mm}$ ) days was undertaken. However, the results of the Kolmogorov-Smirnov test would lead to the rejection of the null hypothesis ( $>80 \%$ of months), indicating that in this case the data is not gamma-distributed.

In the author's opinion this study shows the potential of the modelling of precipitation PDF and the results are encouraging in terms of the possibility of developing projections for the $21^{\text {st }}$ century. Efforts should be made to improve model performance by establishing more reliable links between regional forcing and the variability of the gamma parameters.

\section{Bibliography}

Benestad R.E., 2004, Empirical-statistical downscaling in climate modeling, Eos, Transactions AGU, 85 (42), 417-422, DOI: $10.1029 / 2004 \mathrm{EO} 420002$

Benestad R.E., 2007, Novel methods for inferring future changes in extreme rainfall over Northern Europe, Climate Research, 34, 195-210, DOI: $10.3354 /$ cr00693

Benestad R.E., Achberger C., Fernandez E., 2005, Empiricalstatistical downscaling of distribution functions for daily precipitation, Climate 12/2005 report, www.met.no

Biernacik D., Filipiak J., Miętus M., Wójcik R., 2010, The variability of thermal conditions in Poland since 1951. The results of KLIMAT research project. Klimat Polski na tle klimatu Europy. Zmiany i ich konsekwencje, Seria: Studia i Prace z Geografii i Geologii, 16, 9-21 (in Polish with English summary)

Busuioc A., von Storch H., Schnur R., 1999, Verification of GCM-generated regional seasonal precipitation for current climate and of statistical downscaling estimates under changing climate conditions, Journal of Climate, 12 (1), 258-272, DOI: $10.1175 / 1520-0442-12.1 .258$

Charles S.P., Bates B.C., Whetton P.H., Hughes J.P., 1999, Validation of downscaling models for changed climate conditions: case study of southwestern Australia, Climate Research, 12, 1-14, DOI: $10.3354 / \mathrm{cr} 012001$

Crutcher H.L., 1975, A note on the possible misuse of the Kolmogorov-Smirnov test, Journal of Applied Meteorology, $14,1600-1603$

Essenwanger O.M., 1986, World Survey of Climatology. General Climatology 1B. Elements of Statistical Analysis, Elsevier, $424 \mathrm{pp}$.

Filipiak J., 2004, Variability of air temperature on the Polish coast of the Baltic Sea and Pomeranian Lakeland in the second half of the 20th century, IMGW Warszawa, $216 \mathrm{pp}$. (in Polish with English summary)

Fowler H.J., Esktröm M., Blenkinsop S., Smith A.P., 2007,
Estimating change in extreme European precipitation using a multimodel ensemble, Journal of Geophysical Research: Atmospheres, 112, D18104, DOI:10.1029/2007JD008619

Groisman P.Y., Karl T.R., Easterling D.R., Knight R.W., Jamason P.F., Hennesey K.J., Suppiah R., Page C.M., Wibig J., Fortuniak K., Rauvaev V.N., Douglas A., Forland E., Zhai P.-M., 1999, Changes in the probability of heavy precipitation: important indicators of climatic change, Climatic Change, 42, 243-283, DOI:10.1023/A:1005432803188

Hanssen-Bauer I., Førland E.J., Haugen J.E., Tveito O.E., 2003, Temperature and precipitation scenarios for Norway: comparison of results from dynamical and empirical downscaling, Climate Resarch, 25, 15-27, DOI:10.3354/cr025015

Hanssen-Bauer I., Achberger C., Benestad R.E., Chen D., Førland E.J., 2005, Statistical downscaling of climate scenarios over Scandinavia, Climate Research, 29, 255-268, DOI:10.3354/ cr029255

Haylock M.R., Goodess C.M., 2004, Interannual variability of European extreme winter rainfall and links with mean largescale circulation, International Journal of Climatology, 24, 759-776, DOI:10.1002/joc.1033

Haylock M.R., Cawley G.C., Harpham C., Wilby R.L., Goodess C.M., 2006, Downscaling heavy precipitation over the United Kingdom: a comparison of dynamical and statistical methods and their future scenarios, International Journal of Climatology, 26, 1397-1415, DOI:10.1002/joc.1318

Husak G.J., Michaelsen J., Funk C., 2007, Use of the gamma distribution to represent monthly rainfall in Africa for drought monitoring applications, International Journal of Climatology, 27, 935-944, DOI:10.1002/joc.1441

Huth R., 1999, Statistical downscaling in central Europe: evaluation of methods and potential predictors, Climate Research, 13, 91-101, DOI:10.3354/cr013091

Katz R.W., 1999, Extreme value theory for precipitation: sensitivity analysis for climate change, Advances in Water Resources, 23, 133-139, DOI:10.1016/S0309-1708(99)00017-2

Kalnay E., Kanamitsu M., Kistler R., Collins W., Deaven D., Gandin L., Iredell M., Saha S., White G., Woollen J., Zhu Y., Chelliah M., Ebisuzaki W., Higgins W., Janowiak J., Mo K.C., Ropelewski C., Wang J., Leetmaa A., Reynolds R., Jenne R., Joseph D., 1996, The NCEP/NCAR 40-year Reanalysis Project, Bulletin of the American Meteorological Society, 77, 437-471, DOI:10.1175/1520-0477(1996)077< 0437:TNYRP $>2.0$. CO;2

Kundzewicz Z.W., Radziejewski M., Pińskwar I., 2006, Precipitation extremes in the changing climate of Europe, Climate Research, 31, 51-58, DOI:10.3354/cr031051

Łupikasza E., 2010, Spatial and temporal variability of extreme precipitation in Poland in the period 1951-2006, International Journal of Climatology, 30, 991-1007, DOI:10.1002/joc.1950 Maraun D., Wetterhall F., Ireson A.M., Chandler R.E., Kendon E.J., Widmann M., Brienen S., Rust H.W., Sauter T., Themeß1 M., Venema V.K.C., Chun K.P., Goodess C.M., Jones R.G., Onof C., Vrac M., Thiele-Eich I., 2010, Precipitation downscaling under climate change. Recent developments to bridge the gap between dynamical models and the end user, Reviews of Geophysics, 48, RG3003, DOI:10.1029/2009RG000314 
Marosz M., Wójcik R., Biernacik D., Jakusik E., Pilarski M., Owczarek M., Miętus M., 2011m Poland's climate variability 1951-2008. Klimat project's resultsm Prace i Studia Geograficzne, 47, 51-66 (in Polish with English summary)

Marosz M., Jakusik E., Miętus M.,, 2012, Selected aspects of relation modelling between regional baric field and air temperature on the Polish Baltic Sea coast with the application of statistical-empirical downscaling, [in:] Rola cyrkulacji atmosferycznej w kształtowaniu klimatu, Z. BielecBąkowska, E. Łupikasza, A. Widawski (Eds.), Uniwersytet Śląski, Sosnowiec (in Polish with English summary)

Marosz M., Wójcik R., Pilarski M., Miętus M., 2013, Extreme daily precipitation totals in Poland during summer: the role of regional atmospheric circulation, Climate Research, 56, 245-259, DOI:10.3354/cr01155

Marosz M., Jakusik E., 2014, Downscaling of PDFs of daily air temperature in northern Poland: assessment of predictors, Meteorologische Zeitschrift, (in press), DOI: 10.1127/09412948/2014/0467

Miętus M., Filipiak J., Owczarek M., Jakusik E., 2005, The variability of pluvial conditions in the Baltic Sea Coast: results based on the quantile classification, Materiały Badawcze IMGW, Seria: Meteorologia, 37, 59 pp. (in Polish with English summary)

Miętus M. (Eds.), Wojtkiewicz A., Malik P., Filipiak J., Jakusik E., 2008, Statistical-empirical model of thermal conditions in Poland, Seria: Monografie IMGW, Warszawa, 119 pp. (in Polish with English summary)

Miętus M., (Ed.), Wojtkiewicz A., Wójcik R., Jakusik E., Pilarski M., 2010, Statistical-empirical model of pluvial conditions in Poland, Seria: Monografie IMGW, Warszawa, 75 pp. (in Polish with English summary)

Mooley D.A., 1973, Gamma distribution probability model for Asian summer monsoon monthly rainfall, Monthly Weather Review, 101, 160-176, DOI: 10.1175/1520-0493(1973)101<0160:GDPMFA > 2.3.CO;2

O'Gorman P.A., Schneider T., 2009, The physical basis for increases in precipitation extremes in simulations if 21 stcentury climate change, Proceedings of the National Academy of Sciences of the USA, 106 (35), 14773-14777

Pall P., Allen M., Stone D., 2007, Testing the Clausius-Capeyron constraint on changes in extreme precipitation under $\mathrm{CO}_{2}$ warming, Climate Dynamics, 28, 351-363, DOI:10.1007/ s00382-006-0180-2

Pilarski M., Wójcik R., Biernacik D., Filipiak J., Jakusik E., Marosz M., Owczarek M., Miętus M., 2011, Climatological conditions, [in:] The Polish coastal zone of the Baltic Sea selected environmental issues from 1986-2005, M. Miętus, M. Sztobryn (Eds.), Seria: Monografie IMGW, Warszawa, 19-55 (in Polish with English summary)

Räisänen J., 2007, How reliable are climate models?, Tellus, 59A, 2-29, DOI: 10.1111/j.1600-0870.2006.00211.x

Sauter T., Venema V., 2011, Natural three-dimensional predictor domains for statistical precipitation downscaling, Journal of Climate, 24, 6132-6145, DOI: 10.1175/2011JCLI4155.1

Semenov V.A., Bengtsson L., 2002, Secular trends in daily precipitation characteristics: greenhouse gas simulation with a coupled AOGCM, Climate Dynamics, 19, 123-140, DOI: 10.1007/s00382-001-0218-4

STARDEX, 2005, Recommendation on the more robust statistical and dynamical downscaling methods for the construction of scenarios of extremes, Deliverable D16 - Summary Report

Vlček O., Huth R., 2009, Is daily precipitation gamma-distributed? Adverse effects of an incorrect use of the KolmogorovSmirnov test, Atmospheric Research, 93, 759-766, DOI: 10.1016/j.atmosres.2009.03.005

von Storch H., 1995, Spatial patterns: EOFs and CCA, [in:] Analysis of Climate Variability: Application of Statistical Techniques, H.von Storch, A. Navara (Eds.), Springer-Verlag

Werner P.C., von Storch H., 1993, Interannual variability of Central European mean temperature in January-February and its relation to large-scale circulation, Climate Research, 3, 195207

Wilby R.L., Wigley T.M.L., 2000, Precipitation predictors for downscaling: observed and general circulation model relationships, International Journal of Climatology, 20, 641-661, doi:10.1002/(SICI)1097-0088(200005)20:6<641::AIDJOC501>3.0.CO;2-1

Wilks D.S., 2006, Statistical Methods in the Atmospheric Sciences, Second Edition, International Geophysics Series, 91, Academic Press, 649 pp.

Ziemiański M., Wójcik L., 2003, Meteorological conditionings of the flood in Gdańsk on the 9th July 2001, [in:] The flood in Gdańsk 2001, J. Cyberski (Ed.), GTN, Gdańsk, 57-68 (in Polish)

Zolina O., Kapala A., Simmer C., Gulev S.K., 2004, Analysis of extreme precipitation over Europe from different reanalyses: a comparative assessment, Global Planet. Change, 44, 129161, DOI: 10.1016/j.gloplacha.2004.06.009 